\title{
Empirical Study on the Differences and Influencing Factors of E-commerce Cognitive Behavior of New Type Agricultural Managers
}

\author{
Xian Zhang \\ College of Economics and Management, Yunnan Agricultural University, Kunming, Yunnan, 650000 \\ Email:zhangxian266@126.com
}

Keywords: Empirical Study, Influencing Factors, Cognitive Behavior, Agricultural Managers

\begin{abstract}
The main body of the new type of agriculture is the core force of the development of China's agricultural products e-commerce and the reform of the agricultural supply side. Providing effective policy support and encouragement to different types of new agricultural operators is a top priority for pushing forward the development of rural e-commerce and the reform of the agricultural supply-side. Based on the investigation of 823 new-type agricultural managers in Yunnan province, we use empirical Logistic model to analyze the differences and influencing factors of each type of new-type agricultural operators, Cognitive behavior is different. Among them, the cognition behavior of e-commerce operators such as family farms, growers and growers is stronger than that of large-scale operators such as cooperatives and agricultural enterprises. The cognition of e-commerce of family farms and growers is significantly affected by the scale of operation, not affected by the type of industry, while cooperatives and agricultural enterprises are the opposite. External factors have little effect on the cognitive behavior of e-commerce operators, but the difference is larger. Therefore, in order to better promote the development of rural e-commerce, we should not only focus on setting up rural e-commerce technology forums to enhance farmers' e-commerce awareness, but also strengthen rural e-commerce infrastructure construction and optimize the environment for technology promotion. We should also speed up the construction of electricity Business professionals network, expand the main business community of agricultural business circles.
\end{abstract}

\section{Introduction}

At present, there are many scholars in China who have conducted research on the status quo and characteristics of E-commerce of agricultural products in China, e-commerce platform, product supply chain, operation mode and comparison, agricultural products logistics and technology, legal mechanism of transaction, development problems and countermeasures Relatively rich research results and theoretical system, but the research related to e-commerce of new agricultural products is still relatively small. Tan Xuewen and other research aimed at returning home migrant workers entrepreneurship model simply referred to encourage returning migrant workers to start family farm e-commerce, but did not conduct an in-depth discussion of the main business of electricity suppliers. He Dehua et al. Although studied the willingness of agricultural products e-commerce in the fresh produce e-commerce, they only discussed from the consumers' perspective and did not involve the producers of agricultural products (that is, the main agricultural operators). In short, although scholars in the field of agricultural economy pay special attention to e-commerce of agricultural products and related topics at present, their research time is short and their understanding is not deep enough. However, the e-commerce of agricultural products involves a wide range of issues, the relationship is complex, and there are more and more uncertainties. Research on the Behavior of E-commerce from the Angle of Agricultural Business Entity (Producer). In view of this, based on the in-depth interviews and investigations of 823 new-type agricultural managers in Yunnan Province, this article will use the orderly Lo-gistic model to start with four different types of management entities, namely, family farms, large households, cooperatives and agricultural enterprises Conduct empirical analysis to clarify the difference between the cognitive behavior of 
their agricultural products e-commerce, analysis of the causes of the differences and the influencing factors for the government to promote rural e-commerce offer advice and suggestions.

\section{The Theoretical Model, Variable Selection and Data Description}

The new technology can be transformed into productivity only when it is adopted by the agricultural subject. The cognition of the new agricultural technology by agricultural operators on the e-commerce of agricultural products is the basis for their trial, adoption and promotion. Compared with the ordinary agricultural retail investors, the new agricultural operators have great advantages and demonstration effects in the selection and adoption of new technologies, and study their adoption and cognition of new agricultural technologies such as e-commerce, Very important meaning. In the popularization of agricultural technology, the main body of the agricultural new technology adoption process can be divided into cognitive, persuasion, evaluation, trial, confirmation five stages, this article on the basis of integration of Bandura's human behavior model, the construction of agriculture The main body of business cognitive behavior model.

The dependent variable is the cognition to the e-commerce business of the new-type agricultural business entity. The independent variables include internal factors such as age, educational level, working experience, industry type, scale of operation, gross income, e-commerce infrastructure and trademark registration, Family support, training times, contacts, policy support and other external factors. The choice of specific variables, meaning and assignment, mean, variance and explanatory variables.

Among the internal factors, from the perspective of new agricultural operators, men are more likely to take risks than females, and the adoption of e-commerce technology by new-type agricultural operators is a risky activity. Therefore, it is expected that gender will recognize the new type of agro-business operators The influence of knowing is positive; the older the main body of agriculture is, the more difficult it is to renew its thinking and the more stable the character is, the less it is detrimental to the adoption of e-commerce technology. Therefore, the expected age has a negative impact on the e-commerce cognition of the new type of agricultural operating entity; Therefore, the expected impact of education is positive; going out to work enriches the social experience of the main agricultural operators and broadens the horizons of the main players in agricultural operations. Therefore, the higher the education level is, the better the educational attainment is. Expected impact of working experience is positive; from the perspective of the new type of agricultural management, the expected impact of the type of industry engaged is negative, because the higher the degree of specialization, agricultural products tend to be more specialized and modern in the sales process, the easier it is to adopt agricultural e-commerce technology The modest scale of agricultural operations has been agreed by academics (16) The larger the operating area (size) is not the better, the expected impact on e-commerce awareness is not yet known. The higher the operator's income is, the easier it is to update production equipment and adopt new technologies. Therefore, the expected impact is positive. The more perfect the e-commerce infrastructure, the more conducive to the adoption of agro-products e-commerce technology by the new type of agro-business entities, so the expected impact is positive; the agro-business owners of registered trademarks tend to be more regulated in their operations, stronger in brand awareness and more on the online sales of brands Valuable, so the expected impact is positive.

Among the external factors, the support of family members to the operators' e-commerce behavior and the connections among managers are also important, so the expected impact is positive; the policy support funds can directly increase the incomes of farmers, enhance the confidence of managers, in recent years, the training of peasants' vocational skills held by the government has far-reaching impact on the main body of new-type agricultural operations. However, due to the large gap between training content and actual demand, the greater the number of trainees who attend the training, the greater the impact, the expected impact is not yet known. So, internal and external factors on the new type of agricultural business e-commerce cognitive behavior is consistent with expectations? How is its impact? What is the difference between the cognitive behavior of the main business? These need to be followed by a rigorous empirical analysis. 


\section{Empirical Results}

In this paper, STATA14.0 software, first of all, the overall sample (total model) are estimated, the estimated results shown in Table 2, respectively, the estimated coefficient, standard deviation, $\mathrm{Z}$ statistics and the corresponding $\mathrm{P}$ value. On the whole, the cognitive behavior of e-commerce operators in new-type agro-business entities is significantly affected by the combination of internal and external factors, with only insignificant impact on gross receipts and training times. Specifically, among the internal factors, the estimated coefficient of gender is 0.4599 , which is in line with the expectation and is significant at the level of $10 \%$, indicating that the dominant behavior of male agribusiness operators is significantly better than that of females. The age of the operators had a significant but negative impact on the cognitive behavior of the e-commerce operators, which was in line with the expectation, indicating that young agricultural operators were more willing to adopt new technologies such as e-commerce than their elders. The level of education is significant at the level of $1 \%$, and the coefficient is positive, which is in line with the expectation. It shows that the higher the cultural level of the new-type agricultural operators, the easier it is to accept new agricultural technologies. The estimated coefficient of working experience is significant and positive, indicating that there is a big difference between the attitude of having the working experience and the technology of farm products e-commerce. The working experience can promote the adoption of the e-commerce technology of agricultural products. Push migrant workers back home wave, encourage them to return home to engage in agricultural business activities. The impact of industry type is significantly negative, indicating that the type of industry has a negative impact on the cognitive behavior of the new type of agricultural business e-commerce, that is to say, the main agricultural business type of professional business model is better than the hybrid business model in adopting new technology It is necessary to further strengthen the professional operation of the new type of agricultural management entities and gradually abandon the hybrid management model similar to that of traditional agricultural retail investors. The impact of operating land area was significantly negative, indicating that the scale of operation affecting the cognition of agricultural operators is not as large as possible, highlighting the importance of proper scale. The gross income variable is not significant and the coefficient is negative, indicating that the cognitive behavior of e-commerce operators in agriculture is not affected by income, and there is deviation from the expectation. E-commerce infrastructure and trademark registration were both significant and positive at the level of $1 \%$, in line with expectations, indicating that the e-commerce behavior of agricultural operators was significantly affected by the rural information infrastructure and that the registration of trademarks was conducive to enhancing the recognition of e-commerce know. Among the external factors, personal connections, policy support and so on are all significantly positive. It shows that the promotion of new electricity supplier business and the success of the business of new agricultural operators often require extensive network resources, strong management team and government support. Therefore, expanding the interpersonal circle of agricultural management entities and building a network of relationships will not only help business operators learn from each other and enhance peer awareness of e-commerce, but also gradually gain government support, disseminate e-commerce technical information and stimulate technological adoption. Family support has a significant effect on e-commerce awareness but negative, deviating from expectations. The survey found that $91.5 \%$ of the main agricultural operators in the early stages of technology adoption and entrepreneurship have been disturbed by different levels of their families. Therefore, the principal responsible persons should take the initiative in evading the barriers of family and relatives during the adoption of e-commerce. The number of management subjects participating in training has no significant effect on the cognition of the new type of agro-business e-commerce, because the content of training is often out of line with the actual demand. The survey found that $83.96 \%$ of executives said they are willing to engage in e-commerce, but their actual demand is seriously disproportionate to that of government training. There is almost no access to real and useful technology for training. Thus we can see that training for peasants must be innovative, reform content and practice. 


\section{Conclusion}

Vigorously open rural electricity supplier technology forum to enhance farmers e-commerce awareness. Enhance the cognitive level of the main business operators of electricity is an important part of e-commerce technology promotion. We should innovate the content of professional farmers training and enhance the cognition of e-commerce by focusing on such theoretical courses as e-commerce, agricultural technology training and so on. Classrooms and other practical activities to innovate the technical training of professional farmers to cultivate rural e-commerce talent, to promote aspiring youth with a high cultural quality to become the main agricultural business; by employing e-commerce professionals, the establishment of the village forum, free guidance to answer doubts and promote electricity supplier Technology landing. Encourage successful local agricultural e-commerce operators to set up profit-making technical forums to share their experience in using e-commerce technologies and promote e-commerce technologies from the bottom up to form a demonstration-driven effect. Strengthen the rural electricity supplier information technology facilities, optimize rural technology promotion environment. First, strengthen the planning and construction of rural network facilities, vigorously carry out the "village through the Internet" project construction, through the computer to the countryside, broadband home, Wi-Fi area sharing, etc. to connect rural networks, telecommunications, mobile, China Unicom, radio and television and other Full coverage, the use of resources in the county's existing markets, information, facilities, circulation, regulatory and other resources to establish rural business information application and sharing mechanism to achieve interoperability and resource sharing; Second, focus on improving rural electricity supplier integrated service network, the main construction of the operation center, Telecommunication service center, logistics center and e-commerce service network, etc. It provides rural consumers with such functions as information release, online purchase and sales, offline experience, quality tracing and after-sales service. Finally, the county service center, township service station, village level Service points composed of rural e-commerce service system, optimize the development environment for rural e-commerce.

\section{Acknowledgement}

Yunnan Agricultural University Youth Social Science Fund Project "Yunnan electricity supplier poverty alleviation model and mechanism" phase results

Project No.: 2013PY13

\section{References}

[1] Xie Tiancheng, Shi Zulin. The status quo of rural e-commerce development, problems and countermeasures [J]. Modern Economic Research, 2016 (11): 40-44.

[2] Nie Linhai. Characteristics and trends of e-commerce development in China [J]. China's Circulation Economy, 2014 (6): 97-101.

[3] Zhang Shengjun, Lu Zheng, Deng Xiang. Evaluation and Suggestions on the Construction of Agricultural E-commerce Platform in China [J]. Journal of Rural Economy, 2011 (10): 103-106.

[4] Chen Liang. From the Ali platform for agricultural products e-commerce development trend [J]. China's circulation economy, 2015 (6): 58-64.

[5] Wang Ke, Li Zhen, Zhou Jian. Analysis on the Supply Chain of Agricultural Products with the Participation of E-commerce - A Case Study of Cai Guan Jia [J]. East China Economic Management, 2014 (12): 157-161. 